\title{
Nonlinear integration of evidence in a dynamic motor task
}

\author{
Katja Fiedler ${ }^{1,2^{*}}$, J Michael Herrmann 2,3 \\ From Twentieth Annual Computational Neuroscience Meeting: CNS*2011 \\ Stockholm, Sweden. 23-28 July 2011
}

\section{Introduction}

Reaching movements are governed by estimates of sensory and environmental quantities. If performed under uncertainty they are often based on prior expectations that summarise previous relevant information. We study the temporal evolution of the decision priors in a twoalternative forced-choice movement task.

\section{Methods}

We acquired data from four right-handed and four lefthanded participants who performed an obstacle avoidance task using a manipulandum (Phantom 3.0). In each trial, downward movements were initially directed towards an intermediate target. When arriving at the via-point the location of the final target was revealed which indicated whether the obstacle was to be circumvented on its right or left side. The task was spatially symmetric and the laterality of the final target was overall balanced, the first tens of trial, however, were deliberately weakly biased towards one side. The validity of a trial required reaching the final target within a short time interval by passing the obstacle on the correct side. When departing from the intermediate target, participants often moved briefly towards the wrong side before reverting this preliminary decision and proceeding toward the final target along the correct side. The interim movements were extracted from four blocks of 250 valid trials each for both dominant and non-dominant hand for each participant. The data were statistically analysed using linear models for a local description of the time series of interim movements and a non-linear model for the description of the dynamics of the decision priors.

\footnotetext{
* Correspondence: katja@nld.ds.mpg.de

${ }^{1} \mathrm{MPI}$ for Dynamics and Self-Organization, Bunsenstr. 10, Goettingen, D-37073, Germany

Full list of author information is available at the end of the article
}

\section{Results}

Analysing directional decisions in dependence on a bias in target presentation, we find that all participants have a strong tendency to adopt the initial bias from the presented distribution. This tendency is strengthened during breaks between sessions. Only when a large number of trials that provide evidence to the contrary a small but significant adjustment of the decision strategy is observable. The results are reproduced independently of handedness. After a large number of strongly biased interim movements the subjects tend to realise the suboptimality of their decision strategy and return briefly to a less biased behaviour which is, however, typically unstable. These phenomena are shown to be independent of handedness.

Linear modelling (SARMA) revealed that the movement decision becomes soon nearly independent of the task, but is predictable by earlier movement decisions although information from earlier trials is statistically irrelevant. This effect can be captured for all naïve participants by a non-linear model of symmetry breaking in the decision task. Instead a nonlinear model of decision making is required which involves different time scales for formation of estimates and movement generation.

\section{Conclusion}

Instead of constructing an internal representation of the statistical distribution of the task and their sensory uncertainty, the participants were forming a reflexive prior of their previous actions, while the performance of the task was achieved by reactive control, cf. [1]. Although information from earlier trials is statistically irrelevant, its effect could not be ignored and introduced a strongly biased perception of the task. We conclude that our results do not question the Bayesian paradigm in sensorimotor control, but may introduce an 
inaccurate and potentially suboptimal representation of the environment.

\section{Acknowledgments}

This work was partially supported by DIP F1.2 and BMBF, grants 01GQ0432, 01GQ1005A, and 01GQ1005B. We thank Sascha Wolf, Florentin Woergoetter, Tamar Flash and Sarah Solla for stimulating discussions.

\section{Author details}

'MPI for Dynamics and Self-Organization, Bunsenstr. 10, Goettingen, D-37073, Germany. ${ }^{2}$ BFNT Goettingen, Bunsenstr. 10, Goettingen, D-37073, Germany. ${ }^{3}$ School of Informatics, IPAB \& ILSI, University of Edinburgh, 10 Crichton St, EH8 9AB, Scotland, UK.

Published: 18 July 2011

\section{Reference}

1. Koerding KP, Wolpert DM: Bayesian integration in sensorimotor learning. Nature 2004, 427:244-247.

doi:10.1186/1471-2202-12-S1-P148

Cite this article as: Fiedler and Michael Herrmann: Nonlinear integration of evidence in a dynamic motor task. BMC Neuroscience 2011 12(Suppl 1): P148.

\section{Submit your next manuscript to BioMed Central} and take full advantage of:

- Convenient online submission

- Thorough peer review

- No space constraints or color figure charges

- Immediate publication on acceptance

- Inclusion in PubMed, CAS, Scopus and Google Scholar

- Research which is freely available for redistribution

Submit your manuscript at www.biomedcentral.com/submit 